\title{
The SOLA Award in 2017
}

The Editorial Committee of Scientific Online Letters on the Atmosphere (SOLA) gives The SOLA Award to outstanding paper(s) published each year. I am pleased to announce that The SOLA Award in 2017 is going to be presented to the paper by Dr. Hiroaki Miura, entitled with "Coupling the hexagonal B1-grid and B2-grid to avoid computational mode problem of the hexagonal ZM-grid" (Miura 2017), and to the paper by Dr. Daisuke Goto et al., entitled with "Vertical profiles and temporal variations of greenhouse gases in the stratosphere over Syowa Station, Antarctica" (Goto et al. 2017).

\section{Miura (2017)}

Hexagonal grid, which provides quasi-homogeneous and quasi-isotropic coverage over the sphere, is considered to be an ideal grid system for a high resolution global model. Among the several hexagonal grids, ZM-grid is known to have better properties for the representation of gravity waves than the other grids. However, the ZM-grid has not been adopted for the dynamical core of atmospheric models so far, because it has undesirable influences of computational modes. The author proposed a new hexagonal grid called SB grid (synchronized B-grid) and demonstrated, by using a shallow water model, that this new grid is able to remove the computational modes, while retaining the good performance of the ZM grid. The idea of the proposed SB grid and the results demonstrated with the shallow water model are excellent. The advantage of the present new scheme is expected to be applied to full atmospheric models. This paper is highly evaluated in contributing to the advances in developing high-resolution global atmospheric models.

\section{Goto et al. (2017)}

For the purpose of identifying anthropogenic influences to global climate changes, it is very important to clarify spatial and temporal features of long-term variations of greenhouse gases in the atmosphere including the stratosphere. However, our knowledge of the variations of greenhouse gases still remains insufficient, particularly in the Antarctic region. The authors examined, by collecting air samples in four austral summers between 1998 and 2013, long-term trends of greenhouse gases, i.e., $\mathrm{CO}_{2}$, $\mathrm{CH}_{4}, \mathrm{~N}_{2} \mathrm{O}$, and $\mathrm{SF}_{6}$, in the stratosphere over Showa Station, Antarctica, and clearly demonstrated the temporal and vertical changes of these greenhouse

CThe Author(s) 2018. This is an open access article published by the Meteorological Society of Japan under a Creative Commons Attribution 4.0 International (CC BY 4.0) license (http://creativecommons.org/license/by/4.0). 
gases from the observed data. It was shown that stratospheric $\mathrm{CO}_{2}$ and $\mathrm{SF}_{6}$ above the height of $18 \mathrm{~km}$ gradually increased over the analysis period, but with delays of about 4.5 and 5.6 years, respectively, compared to the tropical troposphere. The increase of stratospheric $\mathrm{CH}_{4}$ was also detected by taking into account the $\mathrm{N}_{2} \mathrm{O}$ depletion during the transport of air from the tropical troposphere to the Antarctic stratosphere. This study is highly valuable in observationally demonstrating the first evidence of the temporal and vertical changes in minor constituents in the Antarctic stratosphere.

Therefore, the Editorial Committee of SOLA highly evaluates the excellence of the two papers.

Tetsuya Takemi

Chief Editor

22 January 2018

\section{References}

Goto, D., S. Morimoto, S. Aoki, S. Sugawara, S. Ishidoya, Y. Inai, S. Toyoda, H. Honda, G. Hashida, T. Yamanouchi, and T. Nakazawa, 2017: Vertical profiles and temporal variations of greenhouse gases in the stratosphere over Syowa Station, Antarctica. SOLA, 13, 224-229, doi: 10.2151/sola.2017-041.

Miura, H., 2017: Coupling the hexagonal B1-grid and B2-grid to avoid computational mode problem of the hexagonal ZM-grid. SOLA, 13, 6973, doi: 10.2151/sola.2017-013.

CThe Author(s) 2018. This is an open access article published by the Meteorological Society of Japan under a Creative Commons Attribution 4.0 International (CC BY 4.0) license (http://creativecommons.org/license/by/4.0). 